\section{More than just a name}

Sir - You report a proposal to 'return' the name of the Royal Greenwich Observatory to the National Maritime Museum at Greenwich (Nature 388, 705; 1997). We have no wish to cause offence to our parent organization, but, as with all children leaving home, there can be no going back.

The Royal Observatory moved from Greenwich in the 1950s, leaving behind a historical museum of artefacts which tell the story of UK astronomy from the foundation of the observatory by Charles II in 1675 until the middle of this century.

The Royal Greenwich Observatory at Cambridge in the 1990s is quite different. It is a modern scientific establishment with a first-class international reputation for achievements in astronomical research, telescope and instrument technology and related activities.

In our view it would be an empty gesture to detach and move the name from the observatory and return it to a museum. Furthermore, the business plan that the observatory's managers are developing to keep it going as a nonprofit organization depends crucially on the worldwide reputation that the name Royal Greenwich Observatory carries.

You suggest that the 'public understanding' arm of the observatory might accompany the move to the museum. Our highly successful programme in this area could not be continued at a museum, and as members of the team we would not wish to try. It is successful because we not only do research ourselves but have access to experts working at the frontiers of astronomy and astronomical technology.

In his statement, the minister for science, John Battle, instructed the Particle Physics and Astronomy Research Council to "explore every avenue for keeping the institution alive”. This institution is more than just a name that can be moved from one building to another.

\section{Margaret Penston}

Robin Catchpole

Royal Greenwich Observatory,

Cambridge CB3 OEZ, UK

Nonfalsifiable hypothesis

Sir - In his review of my book Yes, We Have No Neutrons, Walter Gratzer adopts a dismissive tone that seems to have more to do with my having chosen examples of science-gone-wrong that were not to his particular taste than with the very substantive issues involved (Nature 388, 36; 1997). It is most instructive to watch how research goes off the rails when scientists who think they have made an earthshattering discovery forget the elements of good method. The frailties of ego undermine the discipline needed to make the very tests that will disprove the hypothesis.

In the case of the search for extraterrestrial intelligence (SETI) the hypothesis is nonfalsifiable. This does not make me a student of Karl Popper, but someone who believes that the SETI experiment is only half an experiment, at best. If aliens are sending us messages, the SETI programme is (or was) superbly equipped, we think, to pluck them from the sky. But if aliens are not sending us messages, there is no way the programme can rule out this possibility. Drake and company would merely tighten the bandwidth, add more billions of processors, search more of the sky more of the time and so on. There is no stopping rule: no test for the non-existence of such messages.

Gratzer is incorrect when he claims that receipt of such messages would prove me wrong. Although the book has a certain amount of fun with the idea of what such messages might be like, it makes no claim that they are not, in fact, being sent. It merely asserts that if no recipes for fantastic new discoveries are bathing the planet, we have no way to find out.

The review ends on a profoundly 
discouraging note in which Gratzer feels compelled to quote Werfel: "For those who believe, no explanation is necessary, while for those who do not believe, no explanation is possible."

Has the general readership already hardened into two camps on each of the eight examples of "bad science" explored in the book? I think not. I hope not. Is this a general assertion about the uselessness of making any distinction between good and bad science? One would like to say "science" and "non-science" in place of these adjectives, but, as Gratzer points out, just about everything is called "science" these days.

\section{A. K. Dewdney}

Department of Computer Science,

University of Western Ontario,

London, Canada

e-mail:akd@csd.uwo.ca

\section{Soil without life?}

Sir - Over the past few weeks I have read with great interest your coverage of the discoveries of the Mars Sojourner ${ }^{1}$. There have been many fascinating data reported about the mineral constituents of Mars rocks.

At the same time, however, references are made to martian soil without any data to support the existence of this material. Careless use of the term soil is misleading ${ }^{2}$.

For many in Earth sciences, soil imparts a notion of biological activity for which we have no evidence on Mars. In fact, most definitions of soil are closely linked with plant growth, organic matter or biological activity $^{3-6}$.

Although I do not subscribe to all these definitions of soil and I do not want to limit the study of pedology solely to planet Earth, I also do not envisage all martian dust as martian soil. It may well be that with continued advances in planetary studies we need to re-evaluate the definition of soil. In the meantime it may be prudent to refrain from imparting this earthly quality to all planets.

\section{Daniel Markewitz}

Woods Hole Research Center,

Woods Hole, Massachusetts 02543, USA

e-mail:dmarke@whrc.org

1. Battersby, S. Nature 388, 408 \& 612 (1997).

2. Johnson, D. L. Science 160, 1258 (1968).

3. Dokuchaev, V.V. Russian chernozem. (1883). In Selected works of V. V. Dokuchaev, 1, 14-419 (Moscow, 1948). Israel Prog. Scient. (Transl. Jerusalem, 1967; US Department of Commerce, Springfield, VA.)

4. Byers, H. G. et al. in Soils and Men: Yearbook of Agriculture, 1938 979-1001 (US Department of Agriculture, Washington DC, 1938).

5. Buol, S. W., Hole F. D. \& McCraken R. J. Soil genesis and classification 3rd ed. (Iowa State Univ. Press, Ames, IA, 1989).

6. Wilde, S. A. in Trans. 7th Internat. Cong. Soil Sci. 2, 711-714 (Madison, WI, 1960).

\section{The lost ape}

Sir - Although recent correspondence has highlighted the way in which scientists are increasingly over-indulgent in their use of the concept of novelty (Nature 385, 480 \& $387,843 ; 1997)$, the practice continues.

In a recent contribution to Nature (388, $337 ; 1997)$ entitled "A new west African chimpanzee subspecies?", the authors suggest that "a previously unrecognized type of chimpanzee may be present in Nigeria and adjacent parts of Cameroon", but then go on to point out that if the subspecies is "eventually recognized, the name vellerosus seems to be available".

It would appear, therefore, that J. E. Gray described this potential "new" subspecies more than a century ago, a contribution that should not be overlooked simply because he lacked the technological advantages of polymerase chain reaction. Should not the recent findings be more accurately presented as a case of an old and forgotten subspecies that has been rediscovered and validated using new techniques?

\section{Terry Harrison}

Department of Anthropology,

New York University,

New York, New York 10003, USA

e-mail:harrisnt@is2.nyu.edu 